\title{
PRINCÍPIOS DA MANUFATURA ENXUTA COMO PROPOSTA PARA ARRANJO FÍSICO NA INDÚSTRIA DE TRANSFORMAÇÃO DE TERMOPLÁSTICOS
}

\author{
Robson Pache ${ }^{1}$ \\ Vilmar Bueno Silva ${ }^{2}$ \\ Lucas Almeida dos Santos ${ }^{3}$ \\ Eliane Garlet ${ }^{4}$ \\ Leoni Pentiado Godoy ${ }^{5}$
}

\begin{abstract}
Resumo: A redução de perdas e o aumento dos ganhos se configuram como um dos grandes objetivos das organizações, que por meio da otimização dos processos e consequente agregação de valor, revela a necessidade de investimentos por parte das empresas, garantindo assim, a melhoria contínua de seus processos. O Presente estudo caracterizado como uma pesquisa-ação tem como é desenvolver uma proposta de arranjo físico, que a partir de arranjos atuais e por meio da aplicação de conceitos de manufatura enxuta, servirão de base para o arranjo proposto nesta pesquisa, tendo como cenário uma indústria de transformação de termoplásticos. Os resultados obtidos demonstram a melhor opção de arranjo físico, considerando o tipo de processo da empresa, bem como a estratégia de flexibilidade da mesma. Ainda se apresenta a análise de perdas com o atual arranjo físico, sendo o ponto de partida para a proposta do novo layout, onde estimou-se ganhos no fluxo do processo produtivo como também a redução das sete perdas em cada parte dos processos de manufatura, os quais podem ser adquiridos com a efetiva implementação da proposta de arranjo físico.
\end{abstract}

Palavras-chaves: Processos, Arranjo Físico, Mapeamento de fluxo de valor

Abstract: The reduction of losses and rising earnings are configured as one of the major objectives of organizations, that by optimizing processes and consequent added value, reveals the need for investment by businesses, thus ensuring the continuous improvement of its processes. The present study characterized as an action research is to is to develop a proposal for a physical arrangement, which from current arrangements and through the application of lean manufacturing concepts, form the basis for the arrangement proposed in this research, against the backdrop of one processing thermoplastics industry. The results showed the best physical arrangement option, considering the type of the business process as well as the strategy of flexibility thereof. Still shows the loss analysis with the current physical arrangement, being the starting point for the proposed new layout, which was estimated gains in the flow of the production process and also reducing the seven losses in each of the manufacturing processes, which can be purchased with the effective implementation of the physical arrangement proposal.

Keywords: Processes, Physical Arrangement, Value Stream Mapping

\footnotetext{
${ }^{1}$ Dept $^{\text {o }}$ de Engenharia de Produção, Faculdade de Horizontina. E-mail: pache.robson@ gmail.com

${ }^{2}$ Dept $^{\mathrm{o}}$ de Engenharia de Produção, Faculdade de Horizontina. E-mail: silvavilmarb@ fahor.com.br

${ }^{3}$ Programa de Pós-Graduação em Engenharia de Produção, Universidade Federal de Santa Maria E-mail: luksanttos@gmail.com

${ }^{4}$ Programa de Pós-Graduação em Engenharia de Produção, Universidade Federal de Santa Maria, Email:eligarlet@gmail.com

${ }^{5}$ Programa de Pós-Graduação em Engenharia de Produção, Universidade Federal de Santa Maria, Email:leoni_godoy@yahoo.com.br
} 


\section{INTRODUÇÃO}

Com o aumento da demanda dos mercados e o desenvolvimento acelerado nos sistemas de produção, as empresas começaram a buscar alternativas de redução de custos internos, buscando redução de desperdícios, otimização de recursos, melhora no fluxo e consequente, ganho no desempenho do sistema como um todo.

Aplicar conceitos que irão diminuir a movimentação dos materiais e usar de forma otimizada os recursos, torna-se parte fundamental da gestão das operações dentro das empresas, dessa forma um arranjo físico planejado de forma inadequada e sem a devida análise do processo, pode fazer com que a empresa tenha problemas que afetarão a produtividade, a qualidade dos produtos e seus processos internos.

As perdas decorrentes do processo produtivo têm influência direta nos resultados finais da organização, assim identificar e controlar essas perdas é tarefa imprescindível porque permitirá desenvolver processos que possibilitem otimizar os níveis de entrega, de eficiência, de qualidade, entre outros. Nesse contexto a definição do layout torna-se estrategicamente importante, pois permite a diminuição de algumas perdas relacionadas ao fluxo de produção.

Determinar a distribuição ótima dos layouts é um problema que tem sido extensivamente estudada e para o qual várias metodologias foram geradas ao longo de vários anos (Salazar, et al., 2010). Encontrar uma solução para este problema é importante para qualquer empresa, dado o impacto que tem sobre o estágio de planejamento e execução de operações e tendo em conta as consequências diretas sobre a sua eficácia e eficiência, porque afeta as relações entre os vários fatores e processos de layouts (Wang et al., 2008).

A empresa estudada tem um alto custo dentro do seu processo de manufatura e uma das causas é o layout atual, devido movimentações de produtos como matérias-primas, semiacabados, produtos prontos que efetivamente não agregam valor e são realizadas em várias partes do processo. Outras questões que precisam ser ressaltadas são o elevado índice de ruído das máquinas que contribui na redução da produtividade e as não conformidades que ocorrem em virtude das movimentações entre os setores.

Atualmente a manufatura da empresa é composta pelos processos de extrusão, usinagem, reciclagem e injeção, pelo arranjo físico atual existem perdas decorrentes de movimentações desnecessárias, por estoques, esperas, produtos defeituosos e inventários desnecessários. Dessa forma, o estudo de uma nova proposta de layout se faz necessário, de modo que essas perdas possam ser analisadas e a partir disso seja possível configurar um arranjo que as elimine ou diminua em porcentagem expressiva, vindo ao encontro da construção de uma nova fábrica.

Desta forma, o objetivo deste trabalho é desenvolver uma proposta de arranjo físico, que a partir de arranjos atuais e por meio da aplicação de conceitos de manufatura enxuta, servirão de base para o arranjo proposto nesta pesquisa, tendo como cenário uma indústria de transformação de termoplásticos.

\section{REFERENCIAL TEÓRICO}

Com o objetivo de identificar as questões relativas ao tema do estudo, o referencial teórico torna-se importante para o delineamento e encaminhamento do trabalho.

\subsection{Caracterização de arranjo físico} produtiva preocupa-se com $\mathrm{o}$ posicionamento físico dos recursos de transformação. Colocado de forma simples, definir o arranjo físico é decidir onde colocar todas as instalações, máquinas, equipamentos e pessoal da produção (Slack et al., 2002).

Em outras palavras, arranjo físico é à disposição de máquinas, 
equipamentos e instalações visando à obtenção do melhor fluxo produtivo dentro de uma planta industrial. Para o planejamento de arranjo físico quatro princípios importantes que devem ser levados em consideração (Machline, 2000, apud Silva et al., 2012):

- Princípio da economia do movimento

- Reduzir a distância percorrida;

- Princípio do fluxo progressivo Movimento ininterrupto entre as operações;

- Princípio da flexibilidade - A possibilidade adaptar o arranjo à mudanças;

- Princípio da integração - A integração entre os fatores é necessária para que o arranjo físico seja ótimo.

Para Gaither e Frazier (2001), os layouts das instalações atuais são projetados com a meta última de produzir produtos e serviços que atendam as necessidades dos clientes. Isso significa que os layouts devem ser capazes de produzir produtos rapidamente, a fim de entregá-los rapidamente ao cliente.

A análise de layout auxilia também na obtenção do arranjo físico adequado para cada empresa, uma vez que existem diversos tipos de layout, cada um deles com suas vantagens e desvantagens. Se a organização antecipa uma análise, com certeza, na hora de implantar, vai optar pelo modelo que melhor se adéqua à sua empresa (Carvalho et al., 2010).

De acordo com Borba (1998), o layout visa harmonizar e integrar equipamento, mão de obra indireta, enfim todos os processos e os itens que possibilitam sua manufatura. Através disso tem-se uma combinação ótima das instalações industriais e de tudo que concorre para a produção, dentro de um espaço disponível.

Em relação aos objetivos, existem dois tipos de arranjo físico (Sossanovicz, 2010): os de natureza qualitativa e aqueles de natureza quantitativa, os objetivos qualitativos tratam de parâmetros que não podem ser quantificados, ao passo que dos objetivos quantitativos estão em minimizar o custo total, minimizar o maior custo, minimizar o tempo de espera, minimizar o tempo total de lotes, entre outros.

\subsection{Tipos de Layout}

Para Costa (2004), as características dos níveis de volume e variedade de produtos ou serviços vão reduzir a escolha de cada tipo de arranjo físico. A decisão pela escolha é influenciada por um entendimento correto das vantagens e desvantagens de cada um.

Para Gaither e Frazier (2001) são cinco os tipos básicos de layouts para instalações de manufatura: processo, produto, manufatura celular e posição fixa e mista.

Borba (1998) comenta que o tipo de arranjo físico é a forma geral do arranjo de recursos produtivos da operação e é em grande parte, determinado pelo tipo de produto, o tipo de processo de produção e o volume de produção.

Slack, Chambers e Johnston (2002) descrevem que, na prática a maioria dos arranjos físicos provém de quatro tipos básicos de layout que são: posicional, por processo, celular e arranjo físico por produto.

Um tipo de processo não necessariamente implica na utilização de um tipo básico de arranjo físico em particular, essa relação que existe entre os tipos de processo e os tipos básicos de arranjo físico não necessariamente determina a escolha do layout (Slack, et al., 2002).

Os mesmos autores salientam que a decisão de qual tipo de arranjo físico adotar raramente envolve uma escolha entre os quatro tipos básicos. As características de volume e variedade de uma operação vão reduzir a escolha. É importante analisar essas características de modo que quando o volume é baixo e a variedade é alta o fluxo não é uma questão central sendo assim com volumes maiores e variedades menores a importância aumenta e a decisão do fluxo 
perpassa pela escolha do melhor arranjo físico.

\subsection{Princípios da manufatura enxuta}

A evolução da manufatura enxuta, de uma ferramenta a uma filosofia de gestão, é o pensamento enxuto, que considera o valor, assim como o cliente final o reconhece, como ponto chave para sua essência (Reis, 2004). Na manufatura enxuta, em suas ferramentas e práticas, se analisadas criteriosamente em seu âmago, é possível verificar que ela atinge a todos os critérios competitivos, como o custo, a qualidade, a rapidez, a flexibilidade e a confiabilidade (Rosa, 2011).

A literatura acerca da gestão enxuta parece convergir ao pressuposto de que a eficácia estaria limitada a contextos de manufatura discreta e repetitiva, onde foi inicialmente desenvolvido (Bortolotti, Danese e Romano, 2012). A despeito da grande repercussão dos conceitos da Produção Enxuta nas empresas contemporâneas, grande parte dos relatos de sucesso vem da indústria automotiva, especialmente nos arranjos do tipo linha de montagem (Junior, 2012).

O termo Lean, que significa enxuto, surgiu na literatura de negócios, para caracterizar o Sistema Toyota de Produção (Figueiredo, 2006). O Sistema tem a designação Lean por diversos motivos: exige menos esforços humanos para projetar e produzir veículos, menos investimentos por unidade de capacidade de produção, menos fornecedores, menos estoques, registro de menos defeitos, número menor de acidentes de trabalho e redução no tempo entre o pedido feito pelo cliente e a entrega do produto.

O real objetivo desse sistema é a eliminação total das perdas e redução de custos. As perdas são caracterizadas como qualquer atividade que não contribuí para as operações, tais como espera acumulação de peças semiprocessadas, recarregamentos, passagens de materiais de mão em mão (SHINGO, 1996). Na busca de criação de vantagens competitivas, a manufatura enxuta pode ser considerada um sistema de capacitação da manufatura, contribuindo para a construção de uma visão estratégica (Veiga; Lima; Costa, 2008).

De acordo com Almeida (2007), o conceito da filosofia Lean parte do princípio de que há desperdício em todos os lugares em uma organização e ele surge como um antídoto para se fazer cada vez mais com cada vez menos e sempre com o objetivo de oferecer aos clientes o que eles realmente desejam no tempo que necessitarem. O mesmo autor também destaca que, Lean Manufacturing, surge como uma metodologia fundamental às empresas, pois focaliza a redução de desperdício ao mesmo tempo em que aumenta a flexibilidade da produção e garante a qualidade dos produtos e serviços.

Assim, a manufatura enxuta surgiu como uma nova forma de se enxergar a produção em larga escala com foco na redução ou eliminação do desperdício no sistema produtivo por meio de técnicas de melhoria contínua. São sete os tipos de desperdício (Ohno, 1997; Shingo, 1989; Hines; Rich, 1997; Corrêa; Gianesi, 1996) a serem combatidos pelo sistema de manufatura enxuta: superprodução; espera; transporte; estoque; processamento; movimentação e defeitos.

Neste sentido, o presente artigo propõe um formato de arranjo físico, que será desenvolvido no sentido de diminuir estas sete perdas. Os esforços serão direcionados para estimar os ganhos nos processos em que há possibilidade de analisar as melhorias com a redução dos desperdícios internos, no que tange a estrutura de layout.

\subsection{Ferramentas da manufatura enxuta (VSM, SMED, 5S)}

O principal conceito da Produção Enxuta consiste em se especificar o que, de fato, agrega valor para o cliente final e no cumprimento desta especificação por meio de um sistema de produção voltado a excelência, caracterizado por um fluxo nivelado e puxado pela demanda do cliente (Braglia et al., 2006). 
O Mapeamento do Fluxo de Valor (Value Stream Mapping) é o conjunto de todas as atividades que ocorrem desde a obtenção de matéria prima até a entrega ao consumidor do produto final (Nazareno et al., 2001). Ajuda a visualizar mais do que simplesmente os processos individuais, possibilita enxergar o fluxo, auxiliando a identificar mais do que os desperdícios. Mapeia o estado atual e ajuda a identificar as fontes do desperdício e fornece uma linguagem comum para tratar dos processos de manufatura, além disso, torna as decisões sobre o fluxo visíveis, de modo que possa discuti-las, juntar conceitos e técnicas enxutas mostrando a relação entre o fluxo de informação e o fluxo de material, colocando isso em prática no estado futuro.

A simbologia do VSM foi desenvolvida de modo a facilitar a identificação dos desperdícios e suas fontes, o que reforça a sua contribuição para com os objetivos da Produção Enxuta (Rother; Shook, 2005; Cottyn et al., 2011; Lu et al., 2011; Yang et al., 2011).

O método de mapeamento do fluxo de valor é composto por quatro etapas básicas (Rother; Shook, 2005):

a) Seleção de uma família de produtos;

b) Mapeamento do estado atual;

c) Mapeamento do estado futuro;

d) Plano de trabalho $\mathrm{e}$ implementação.

No Brasil difundiu-se o uso da sigla TRF, iniciais de troca rápida de ferramentas, como tradução do Single minute exchange of die (SMED). $\mathrm{O}$ termo setup não se aplica apenas a preparação de uma operação de processamento (Shingo, 2002): referem-se também as operações de inspeção de transporte e de espera. Consequentemente, o método, ou seja, as etapas conceituais, os métodos correspondentes e as técnicas específicas para as melhorias de setups podem ser aplicados exatamente da mesma maneira em todas as operações.
O autor supracitado, ainda formulou a hipótese de que qualquer setup poderia ser executado em menos de 10 minutos e chamou esse conceito de troca rápida de ferramenta, ou TRF que é uma metodologia que auxilia na mudança rápida de uma linha de produção possibilitando, consequentemente, respostas rápidas diante das necessidades do mercado. Apresenta grande vantagem quando aplicada na produção de lotes pequenos de fabricação, pois permite reduzir os estoques intermediários $\mathrm{e}$ custos de inventários.

Segundo Nascimento (2002) os 5Ss são pré-requisitos para a implantação da Gestão da qualidade total e enfoca o ambiente de trabalho da organização, de forma que este ambiente seja simplificado e o desperdício reduzido, acarretando a melhoria dos aspectos relacionados à qualidade e segurança.

$\mathrm{O}$ programa $5 \mathrm{~S}$, juntamente com o gerenciamento visual, é o alicerce da melhoria contínua, proporcionando um ambiente de trabalho organizado, limpo e seguro (Bazarra et al., 2009). Conforme Gavioli et al., (2009), o programa é composto por cinco passos, denominados sensos, que devem ser seguidos:

- Senso de utilização (originário da palavra japonesa seiri); Senso de organização (originário da palavra japonesa seiton);

- Senso de organização (originário da palavra japonesa seiton): consiste na organização dos materiais e ferramentas úteis de modo a agilizar o seu acesso;

- Senso de limpeza (originário da palavra japonesa seiso): consiste na eliminação de sujeiras e suas causas;

- Senso de saúde (originário da palavra japonesa seiketsu): consiste na criação de um ambiente saudável e seguro de trabalho;

- Senso de autodisciplina (originário da palavra japonesa shitsuke): consiste no cumprimento dos quatro sensos anteriores, rotineiramente.

É válido salientar que é necessário efetivamente implementar cada senso, começando pela separação e de forma 
gradativa partir para o próximo, de forma que cada um esteja incorporado a cultura da empresa.

\subsection{Caracterização das indústrias de transformação de termoplásticos}

A Indústria de Artigos plásticos deve ser entendida como o conjunto de empresas dedicadas a produzir uma grande variedade de produtos à base de compostos químicos orgânicos poliméricos obtidos por síntese ou de sustâncias naturais de origem derivado de plantas de petróleo, gás natural, carvão e outros, incluindo: moldes, produzindo peças para máquinas e equipamentos e outros produtos de plástico fabricados (Sandrea; Boscan, 2007).

O processo de transformação de termoplásticos acontece de forma bem simples, a empresa compra a resina dos produtores e/ ou distribuidores e também os masterbatches que são concentrados plásticos elaborados a partir de diversos polímeros, utilizados para colorir (pigmentos) e aditivar todos os tipos de resinas termoplásticas. Nesse caso, este transformador, com o devido auxílio do produtor do masterbatch, adéqua a resina às suas necessidades (PDAPL, 2007).

Na Figura 1 é possível ver todo o processo da indústria de transformação de termoplástico (PDAPL, 2007).

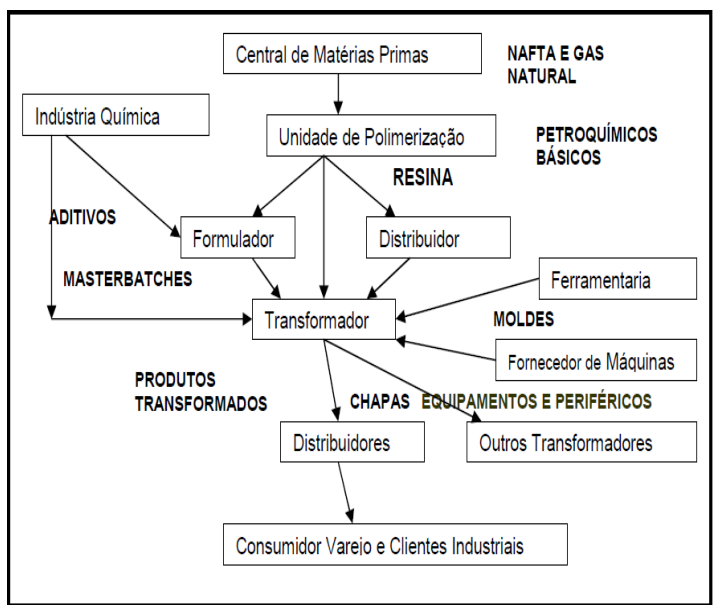

Figura 1 - Cadeia produtiva do plástico. Fonte: Adaptada de PDAPL, 2007.

Referente ao setor de plásticos, a Figura 1 mostra de forma mais simplificada as gerações ou fases em que a cadeia produtiva de plásticos percorre.

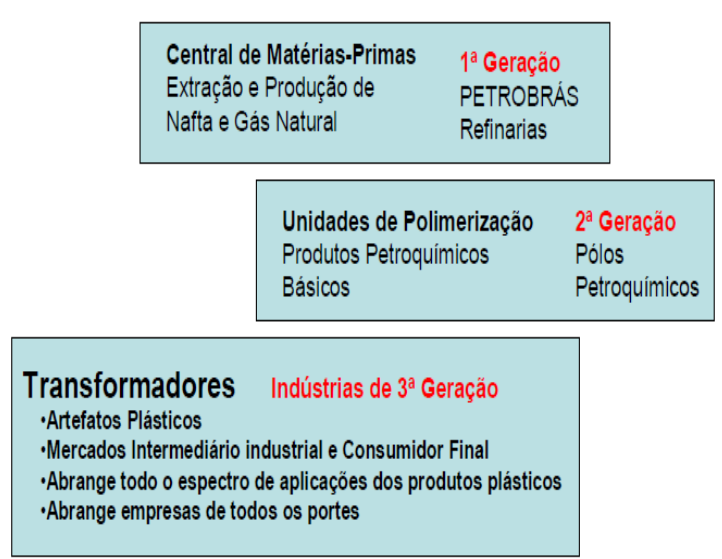

Figura 2 - As Gerações da cadeia produtiva dos plásticos

Fonte: Adaptada de PDAPL, 2007.

Referente ao setor de plásticos, a Figura 2 mostra de forma mais simplificada as gerações ou fases em que a cadeia produtiva de plásticos percorre.

\section{METODOLOGIA}

O presente estudo tem como objetivo desenvolver uma proposta de arranjo físico aplicando conceitos de manufatura enxuta e possui primeiramente, um caráter bibliográfico, fazendo um enlace da teoria com a prática, oportunizando a construção dos resultados a partir da ideia de especialistas da área. Assim, esta pesquisa foi desenvolvida, tendo como objeto de estudo, uma indústria de transformação de termoplásticos localizada na Região Sul do Brasil, a qual trabalha essencialmente com plásticos de engenharia com forte atuação no mercado, com produtos produzidos pela resina Ultra Heigh Molecular Weight (UHMW).

O método utilizado neste estudo é a da pesquisa-ação que consiste em uma pesquisa social com base empírica que é concebida e realizada em associação com uma ação ou com a resolução de um problema coletivo e no qual os pesquisadores e os participantes representativos da situação ou do problema estão envolvidos de caráter cooperativo ou participativo (Cauchick, 2012). 
Atualmente o sistema de controle numérico computadorizado manufatura da empresa trabalha com máquinas extrusoras de projeto próprio, (CNC), entre outras.

esquadrejadeiras de última geração, assim como injetoras, prensas excêntricas, hidráulicas e pneumáticas, máquinas de

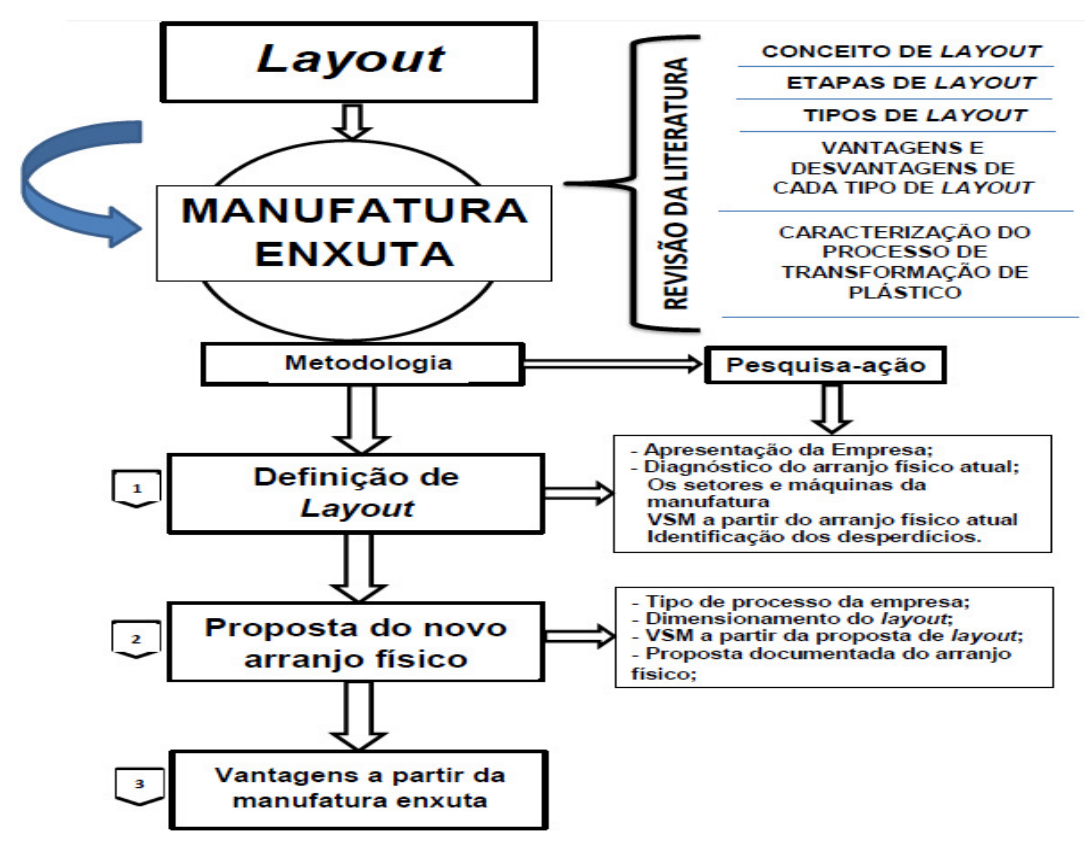

Figura 3 - Fluxograma do delineamento da pesquisa

Logo, este cenário fabril, contribui para o desenvolvimento do trabalho, para o qual foi utilizado, além do método da pesquisa-ação, técnicas de observação e descrição que vão ao encontro de soluções práticas para os problemas reais sucedidos com a análise do ambiente em que a indústria opera.

1) Definição de Layout - Nessa fase do trabalhado, consistiu em definir o tipo de layout mais adequado, considerando os processos produtivos, as atividades realizadas no contexto da produção, o meio ambiente, o espaço disponível, o tipo de máquinas e a estratégia de qualidade e redução de custos da empresa de estudo;

2) Novo Layout - Após terem sido feitos a definição do tipo de layout a ser proposto, e as estimativas de ganhos, foi desenvolvida a proposta de arranjo físico que posteriormente foi documentada. Nessa proposta contempla-se os princípios de manufatura enxuta, naqueles locais onde foi possível adequálos;
3) Estimativa de Ganhos - Etapa do trabalho onde foram feitas as análises no sentido de estimar os ganhos com a proposta de layout nova, essas estimativas foram voltadas a redução das sete perdas dentro da metodologia enxuta.

As ações de redução de custos e consequente ganho em produtividade e diminuição de desperdícios foram sugeridas e adaptadas para o projeto nos processos onde isso foi possível. Dentro dessa amplitude, a estimativa de ganhos foi feita nas partes onde havia possibilidade dessas serem realizadas.

\section{APRESENTAÇÃO E ANÁLISE DOS RESULTADOS}

\subsection{Diagnóstico do arranjo físico antigo}

Atualmente a indústria em foco tem seus processos divididos por duas estruturas prediais, no prédio de maior 
tamanho há o processo de reciclagem que é separado do processo de extrusão e da injeção, porém para haja uma movimentação entre esses, existe uma abertura interna e também a externa na estrutura do prédio.

$\mathrm{O}$ processo de usinagem se encontra num prédio localizado do outro lado da rua, dessa forma a locomoção pela rua é inevitável, o que também propicia a geração de outros problemas, visto que a rua é de calçamento e há a necessidade de movimentar o material entre os mesmos, o que muitas vezes acarreta em quedas do material em processo, podendo vir a danificá-los.

No que tange o processo de reciclagem tem espaço bastante limitado, porque é nesse em que são depositados os Big Bags de matéria prima, como também máquinas grandes como $\mathrm{o}$ micronizador e uma injetora que até então está parada, por falta de um arranjo físico adequado. Ainda nesse prédio, há o triturador que junto com o micronizador produzem muito ruído e também o estoque de matéria prima da injeção e o estoque de produto acabado desse processo.

No local onde se encontra o processo de extrusão e a injeção, os operadores realizam várias movimentações que são para abastecer as máquinas extrusoras, o que acarreta em quedas de matéria-prima visto que a movimentação é feita em sacos plásticos abertos.

No processo de injeção, há também movimentação na preparação da matéria-prima que fica no outro prédio. Para os setups, na extrusão, as ferramentas não estão em local adequado estão jogadas em cima das máquinas, sem local específico, o que acarreta em mais tempo nas trocas. Há geração de estoque intermediário na extrusão, que fica na maioria das vezes, muito tempo em espera. Tais arranjos apresentadas podem ser na Figura 4.

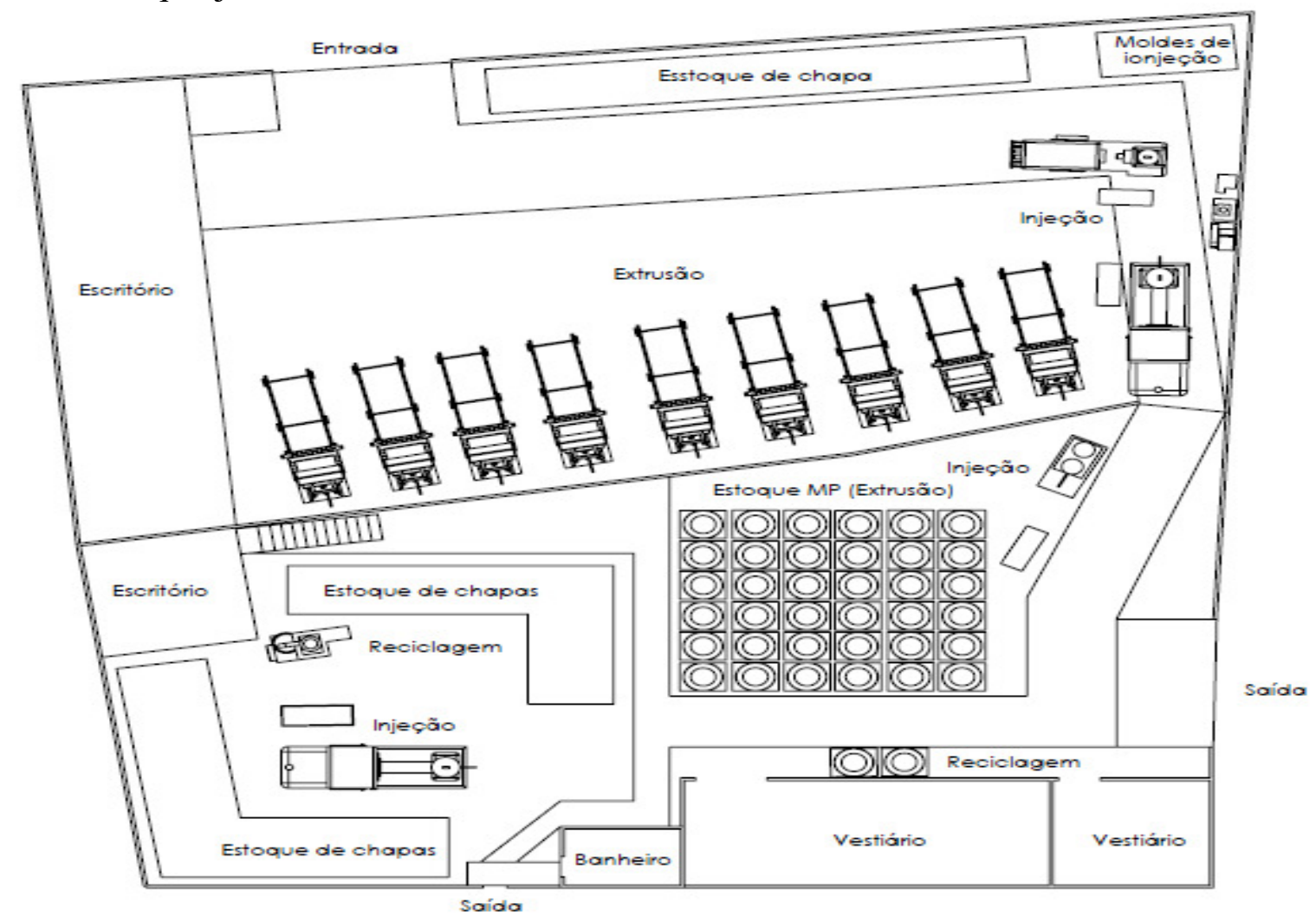

Figura 4- Layout dos setores de extrusão e manufatura atuais.

O ruído gerado pelo micronizador e pelo triturador causa enorme desconforto, com o número de extrusoras existentes e a tendência em aumenta-los, o espaço já é pequeno, se tornará ainda menor, o que reforça a necessidade de uma nova instalação, de um novo arranjo. Para o processo de injeção, não há atualmente um local definido para alocação das máquinas, moldes e 
equipamentos auxiliares, dessa forma, a necessidade da elaboração de um novo arranjo físico se torna muito importante, na medida em que vai possibilitar a alocação de todas as máquinas, equipamento e ferramentas, fazendo com que em haja um fluxo definido e constante.

Assim, este novo arranjo físico propiciará menor impacto a saúde dos colaboradores, visto que existem movimentações com carregamentos, muitas vezes, de volumes com um peso maior. Logo, esse projeto de layout dará condições melhores de trabalho, com diminuição da insalubridade e consequentemente maior produtividade.

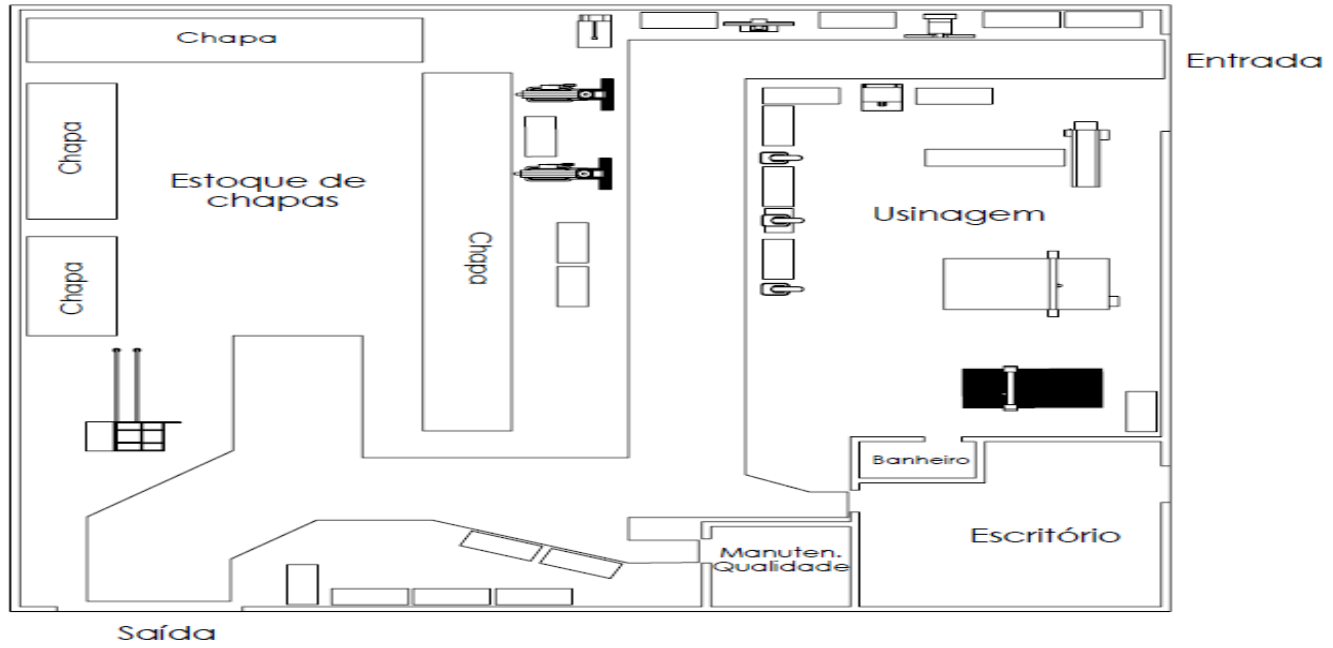

Figura 5: Layout atual do setor de usinagem atual.

No prédio onde se localiza a usinagem, não há um planejamento do ambiente, uma organização baseada em princípios, o que remete ao 5Ss. Existe a criação de pequenos estoques que ficam pelo chão, para serem destinados de forma não prevista ou planejada. Nesse sentido, outro fator que prejudica são as peças que vêm do outro prédio, ou seja da usinagem, onde os operadores colocamnas em locais não identificados, o que desordena todo o fluxo.

Neste ambiente, há também, o estoque de chapas prontas para venda, que estão em prateleiras altas e em locais de difícil manejo, até pelo peso das mesmas, visto que algumas só podem ser retiradas com o uso de uma empilhadeira.
Dentro deste processo e ambiente precisa haver uma organização num sentido metodológico, ou seja, com ações previamente definidas que podem ser realizadas através dos $5 \mathrm{Ss}$, como também a necessidade de locais adequados de armazenamento dos materiais em processo, o que remete ao estudo do melhor fluxo de trabalho. 


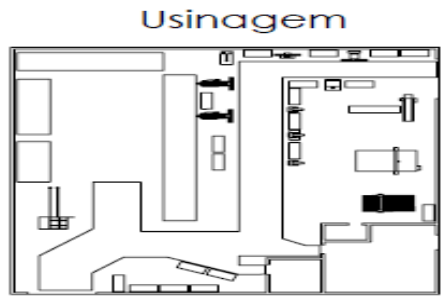

Rua

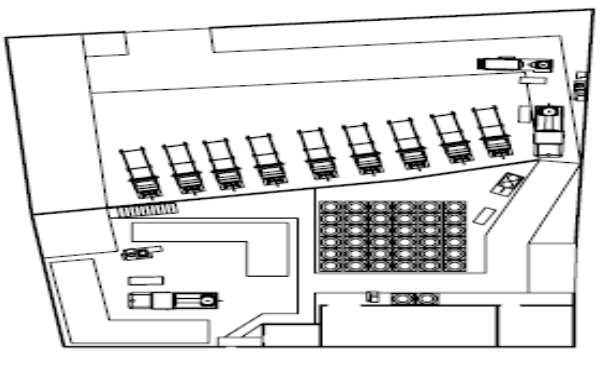

Extrusăo/ reciclagem /injeçăo

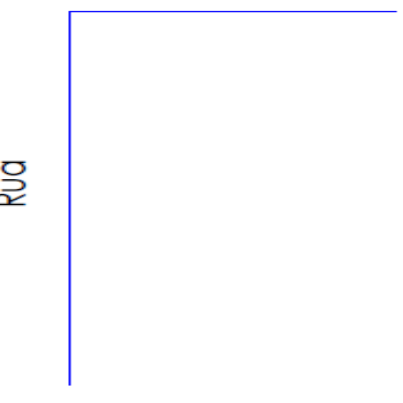

Figura 6: Estrutura da fábrica.

$\mathrm{Na}$ Figura 6, apresenta-se a estrutura da fábrica, colocando os dois prédios, pode ser visto que há uma rua que separa esses, de modo que as movimentações entre ambos sejam inevitáveis.

\subsection{VSM (Value Stream Mapping) a partir do arranjo físico antigo}

A partir da análise do arranjo físico atual, se fez necessário realizar um mapa de fluxo de valor, a fim de observar e estudar os pontos do fluxo onde estão acontecendo as perdas e desperdícios e posteriormente, dentro da proposta de layout futura, fazer as devidas sugestões com o objetivo de otimizar esse fluxo e reduzir as perdas.

No mapa de fluxo de valor atual, que pode ser visto na Figura 7, escolheuse o fluxo de produção dos itens com maior giro na empresa e que tem grande representatividade no faturamento desta.

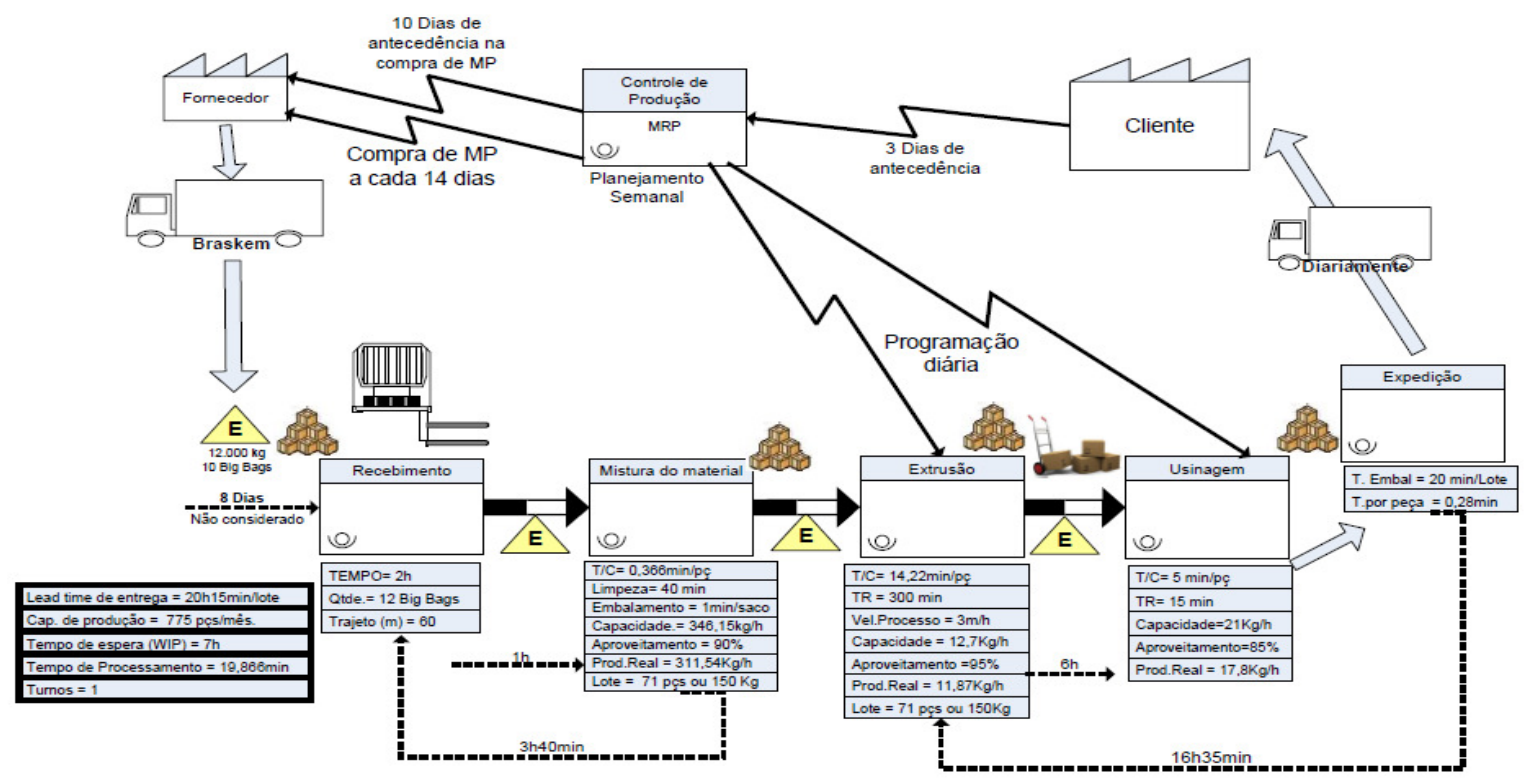

Figura 7: Mapa de fluxo de valor a partir do layout atual.

Para a elaboração desse mapa de fluxo de valor, foi considerado toda a estrutura dos processos de manufatura da empresa, optando-se pelo processo 
contínuo de um dos produtos com mais representatividade em termos de faturamento e que passa por todos os processos de extrusão e usinagem. $\mathrm{Na}$ elaboração desta análise, não foram considerados os processos de injeção, por ser um processo separado da estrutura principal de manufatura, da mesma forma não foi considerado $\mathrm{o}$ processo de reciclagem por se tratar de um processo posterior, visto que aqui se procurou evidenciar o caminho do produto, da chegada da matéria-prima até a saída para o consumidor final, ou seja, a transformação do produto propriamente dito.

Os valores mostrados no VSM retratado na Figura 7 foram obtidos através de medições realizadas efetivamente nos processos, observando o tempo decorrido em cada um desses. Posteriormente as medições realizou-se os cálculos que podem ser observados no Quadro 1.

Quadro 1: Cálculos do mapeamento de fluxo de valor.

\begin{tabular}{|c|c|c|}
\hline PROCESSO & CÁLCULO & RESULTADOS \\
\hline $\begin{array}{l}\text { Tempo de ciclo no } \\
\text { processo de mistura do } \\
\text { Material }\end{array}$ & $\begin{array}{l}\text { Capacidade na mistura é de } 150 \mathrm{Kg} \text {. } \\
\text { Tempo de mistura }=20 \mathrm{~min}+6 \text { min para embalar }(6 \\
\text { sacos } * 25 \mathrm{Kg}=150 \mathrm{Kg}) 20+6=26 \mathrm{~min} . \\
\text { Uma chapa }=12,7 \mathrm{Kg}=6 \text { peças } 150 \mathrm{~kg} / 12,7 \mathrm{Kg}=11,81 \\
\text { chapas } * 6 \text { peças }=71 \text { peças por chapa. }\end{array}$ & $\begin{array}{l}\text { 26min } / 71 \mathrm{pçs}= \\
\mathbf{0 , 3 6 6 m i n / p e c ̧ a ~}\end{array}$ \\
\hline $\begin{array}{l}\text { Tempo de ciclo na } \\
\text { Extrusão }\end{array}$ & $\begin{array}{l}60 \mathrm{~min} \text { para uma chapa de } 3 \mathrm{~m}=6 \text { peças }=10 \mathrm{~min} / \mathrm{pç} \text {. } \\
300 \mathrm{~min} \text { de troca divididos pelo lote de } 71 \text { peças }= \\
4,22 \mathrm{~min} .\end{array}$ & $\begin{array}{l}10 \mathrm{~min}+4,22 \mathrm{~min}= \\
\mathbf{1 4 , 2 2} \mathbf{m i n}\end{array}$ \\
\hline $\begin{array}{l}\text { Tempo de ciclo na } \\
\text { Usinagem }\end{array}$ & $\begin{array}{l}15 \mathrm{~min} \text { de troca dividido por } 6 \text { peças }=2,5 \mathrm{~min} \text { por } \\
\text { chapa. } \\
\text { Corte da chapa }=15 \mathrm{~min} \text { como em uma chapa são } 6 \\
\text { peças }=2,5 \mathrm{~min} \text {. }\end{array}$ & $2,5 \mathrm{~min}+2,5 \mathrm{~min}=\mathbf{5} \mathrm{min}$ \\
\hline Capacidade na Mistura & $\begin{array}{l}150 \mathrm{Kg} \text { por mistura. } \\
\text { Uma mistura=20min }+1 \mathrm{~min} \text { por saco, sendo } 6 \text { sacos, } \\
\text { então=26min. } \\
60 \mathrm{~min} / 26 \mathrm{~min}=2,3 \text { mistura } / \mathrm{hora} * 150 \mathrm{~kg}=346,15 \mathrm{Kg} \text {. }\end{array}$ & $346,15 \mathrm{Kg}$ \\
\hline $\begin{array}{l}\text { Capacidade na } \\
\text { Extrusão }\end{array}$ & $\begin{array}{l}\text { Uma chapa de } 3 \mathrm{~m} \text { tem } 12,7 \mathrm{Kg} \text {, a extrusora produz } \\
3 \mathrm{~m} / \text { hora. }\end{array}$ & $12,7 \mathrm{Kg}$ \\
\hline $\begin{array}{l}\text { Capacidade na } \\
\text { Usinagem }\end{array}$ & $\begin{array}{l}\text { Duas chapas por hora, peso de cada uma é de } 12,7 \mathrm{Kg}= \\
25 \mathrm{~kg} \text {. }\end{array}$ & $\begin{array}{l}25 \mathrm{~kg}-4 \mathrm{Kg} \text { de } \\
\text { perdas }=\mathbf{2 1} \mathbf{~ K g}\end{array}$ \\
\hline
\end{tabular}

Os valores demonstrados nos resultados foram obtidos de forma que no Lead time de entrega sejam somados os valores $3 \mathrm{~h} 40 \mathrm{~min}$ entre os processos de recebimento e mistura, esse valor é a soma do tempo de recebimento de 2 horas, mais o tempo de espera de 1 hora, e mais os 40 minutos de limpeza da mistura. Já o valor de $16 \mathrm{~h} 35 \mathrm{~min}$ é a soma de 5 horas de troca de ferramenta, mais 6 horas de espera, mais 5 horas cronometrados na usinagem, e ainda com os 20 minutos da expedição, somando com 15 minutos de troca de ferramenta na usinagem. Dessa forma, os valores de

soma dos tempos de ciclo encontrados nos processo de mistura, extrusão e usinagem totalizando o valor de 19,6 minutos por peça.
$(3 \mathrm{~h} 40 \mathrm{~min}+16 \mathrm{~h} 35 \mathrm{mim}=20 \mathrm{~h} 15 \mathrm{~min} /$ lote $)$ gerando o valor de lead time de entrega do lote.

O valor da capacidade de produção foi determinado considerando que há 220 horas produtivas no mês, onde aplicando a regra de três simples, que considera as 71 peças do lote, chegando-se ao valor de 775 peças/mês.

Em relação ao tempo de espera, o valor de 7 horas é a soma de 1 hora de espera entre o recebimento e a mistura com as 6 horas de espera entre o processo de extrusão e de usinagem. E por fim, o tempo de processamento é formado pela

\subsection{Identificação dos desperdícios}

A partir da análise do VSM disposto na Figura 7, identifica-se alguns desperdícios, que para fins deste trabalho 
serão relacionados às 7 perdas já conceituadas anteriormente.

Assim, no Quadro 2, são apresentadas, as perdas que foram

identificadas a partir da análise dos processos, essas perdas foram relacionadas dentro das 7 perdas de Ohno.

Quadro 2: Fatores de perda em relação as 7 perdas de Ohno.

\begin{tabular}{|c|c|}
\hline \multicolumn{2}{|c|}{ Fatores de perda percebidos na empresa } \\
\hline \multirow{3}{*}{ Movimentação } & $\begin{array}{l}\text { Os operadores realizam diversas movimentações desnecessárias por entre os prédios, } \\
\text { o que gera maior esforço e retrabalhos. }\end{array}$ \\
\hline & $\begin{array}{l}\text { Há muitas movimentações desnecessárias que são provenientes de deslocamentos de } \\
\text { matéria prima, transferência de peças em processo. }\end{array}$ \\
\hline & $\begin{array}{l}\text { Existem métodos inadequados de trabalho que fazem com que sejam necessárias } \\
\text { movimentações, essas fazem aumentar as atividades sem valor agregado. }\end{array}$ \\
\hline \multirow{2}{*}{ Espera } & $\begin{array}{l}\text { Há esperas por faltas de materiais em processo, o que é causado pela má disposição } \\
\text { dos estoques pulmões entre os processos, principalmente entre a extrusão e a } \\
\text { usinagem. }\end{array}$ \\
\hline & $\begin{array}{l}\text { Há também perdas nesse sentido relacionadas à falta de matéria prima o que causa } \\
\text { maior tempo de prazo de entrega em relação ao previsto, o que é percebido pelos } \\
\text { tempos até a chegada de matéria prima. }\end{array}$ \\
\hline \multirow[b]{2}{*}{ Transporte } & $\begin{array}{l}\text { Há muito deslocamento de produtos entre prédios e dentro dos prédios, o que pode } \\
\text { ser percebido em todos os processos, o que não agrega valor ao produto. }\end{array}$ \\
\hline & $\begin{array}{l}\text { Outra perda relacionada ao transporte são os meios de fazê-lo que são inadequados, } \\
\text { como é preciso fazer transferência de produtos semiacabados e acabados com } \\
\text { empilhadeiras ou carrinhos que são inadequadas para tal aplicação, visto que não } \\
\text { possuem proteções nas extremidades, ou mesmo forma de "pegar" adequada, o que } \\
\text { danifica o produto. }\end{array}$ \\
\hline \multirow{4}{*}{ Estoque } & $\begin{array}{l}\text { Há formação de muitos estoques intermediários, onde muitas vezes há perda de } \\
\text { produtos, no sentido de geração de não conformidades, peças danificadas. }\end{array}$ \\
\hline & $\begin{array}{l}\text { Os estoques gerados entre o processo de extrusão e usinagem são altos e ficam } \\
\text { parados num tempo relativamente alto, o que faz com que o valor real fique parado } \\
\text { por muito tempo. }\end{array}$ \\
\hline & $\begin{array}{l}\text { Os estoques gerados na usinagem e aquele estoque de chapas acabadas que estão } \\
\text { alocados nesse prédio se perduram e se degradam, demandando retrabalhos e } \\
\text { investimentos. }\end{array}$ \\
\hline & $\begin{array}{l}\text { Estoques gerados entre a usinagem e a expedição muitas vezes se deteriora ou se } \\
\text { danifica e permanece no local, ficando muitas vezes obsoleto. }\end{array}$ \\
\hline \multirow{2}{*}{ Defeitos } & $\begin{array}{l}\text { Há muito desperdício pela produção de chapas defeituosas ou não conforme que são } \\
\text { causadas por matéria prima contaminada no transporte ou na mistura. }\end{array}$ \\
\hline & $\begin{array}{l}\text { Há geração de uma grande quantidade de refugos que consumiram matéria prima e } \\
\text { mão de obra, o que muitas vezes acontece por erros no processo em si. }\end{array}$ \\
\hline \multirow{3}{*}{ Processamento } & $\begin{array}{l}\text { Existem operações entre os processos que não agregam nenhum valor, na extrusão o } \\
\text { fato de ter que suprir a cada pouco os funis das extrusoras, os ajustes do estoque com } \\
\text { a empilhadeira a todo o momento. }\end{array}$ \\
\hline & $\begin{array}{l}\text { Na reciclagem o corte de partes de chapas para colocação no triturador é uma } \\
\text { atividade atordoante e que não agrega em nada, a limpeza do micronizador e do } \\
\text { triturador quando há necessidade de troca de cor, que é realizado a toda hora. }\end{array}$ \\
\hline & $\begin{array}{l}\text { Na usinagem quando há necessidade de trocar a chapa na máquina Router, a todo o } \\
\text { momento o operador necessita retirar os calços que prendem a chapa, atividade que } \\
\text { também demanda tempo e não agrega em nada. }\end{array}$ \\
\hline \multirow{2}{*}{ Superprodução } & $\begin{array}{l}\text { A geração de matéria prima reciclada é produzida de uma maneira maior do que a } \\
\text { necessária, ficando muito tempo parado. Isso significa perda e dinheiro parado, o } \\
\text { que acontece muitas vezes pela não visualização dessa superprodução. }\end{array}$ \\
\hline & $\begin{array}{l}\text { Na usinagem, o estoque que é gerado de chapas que em alguns casos foi produzido a } \\
\text { mais do que o pedido, o que é realizado para evitar a repetição da mesma no curto } \\
\text { prazo, mas muitas vezes esse estoque a mais fica parado por muito tempo. }\end{array}$ \\
\hline
\end{tabular}

Com isso, ao averiguar a formatação e estudo do novo layout, pode ser analisada e configurada no sentido de diminuir essas incidências que devem ser tratadas como problemas, uma vez que, as ações dentro da proposta são conduzidas para a redução dessas perdas e consequente diminuição dos desperdícios levantados. 


\subsection{Proposta do novo arranjo físico e do fluxo dos processos}

Posteriormente às análises dos desperdícios percebidos no layout, análises essas que foram realizadas com todo o quadro de operadores que efetivamente estavam inseridos no processo, percebe-se uma necessidade na elaboração de um novo arranjo físico para a indústria em foco.

A empresa pesquisada, levando em consideração as características dos processos e os recursos existentes, verificou-se que o tipo de processo em que a mesma mais se adapta é o de lotes de produção, visto a necessidade de flexibilidade de processo e o alto custo envolvido. No que tange a variedade, percebe-se que não há alta diferença em relação a tal característica, da mesma forma que não há uma baixa variedade.

Em relação ao volume, pode-se dizer que também tem-se uma igualdade em termos de variação, por ter uma demanda bastante oscilante, os volumes em determinadas épocas do ano acabam tendo grandes oscilações. Portanto, a proposta de arranjo físico será norteada pela definição do tipo do processo descrito, ou seja, considerando o processo de lotes, os recursos da manufatura e os espaços necessários. Obstante a isso, o ponto mais importante a considerar na proposta que será apresentada é a estratégia preponderante da empresa, que é a flexibilidade. Neste sentido, a ocupação dos espaços, a adequação aos processos e a questão dos conceitos de manufatura enxuta, serão introduzidos na proposta levando em conta esses aspectos.

\subsection{Proposta documentada do arranjo físico novo}

Após a realização de toda a análise do processo e a definição das tarefas essenciais para um bom desenvolvimento de um arranjo físico, foi elaborada uma proposta para a empresa estudada. Nesta considerou-se os desperdícios percebidos juntamente com todo o grupo de colaboradores e que estão relacionados no Quadro 2, como também foi concebida levando em consideração os princípios básicos da manufatura enxuta.

Na Figura 8 tem-se a disposição de todos os processos, máquinas $\mathrm{e}$ equipamentos da fábrica, de forma que é possível verificar de que forma ficaria o fluxo dos processos. Para a presente pesquisa, não foi necessário um estudo no sentido de relacionar os processos e atividades, pois se identificou que tal processo é visivelmente claro, e como não há tanta diversidade de máquinas, a montagem e estruturação do fluxo, acaba sendo de certa forma mais simples.

A área disponível para a alocação de todas as máquinas e equipamentos, totaliza $5000 \mathrm{~m}^{2}$, sendo distribuída em $50 \times 100 \mathrm{~m}$. Nesta proposta contempla-se toda a estrutura dos processos da manufatura. 


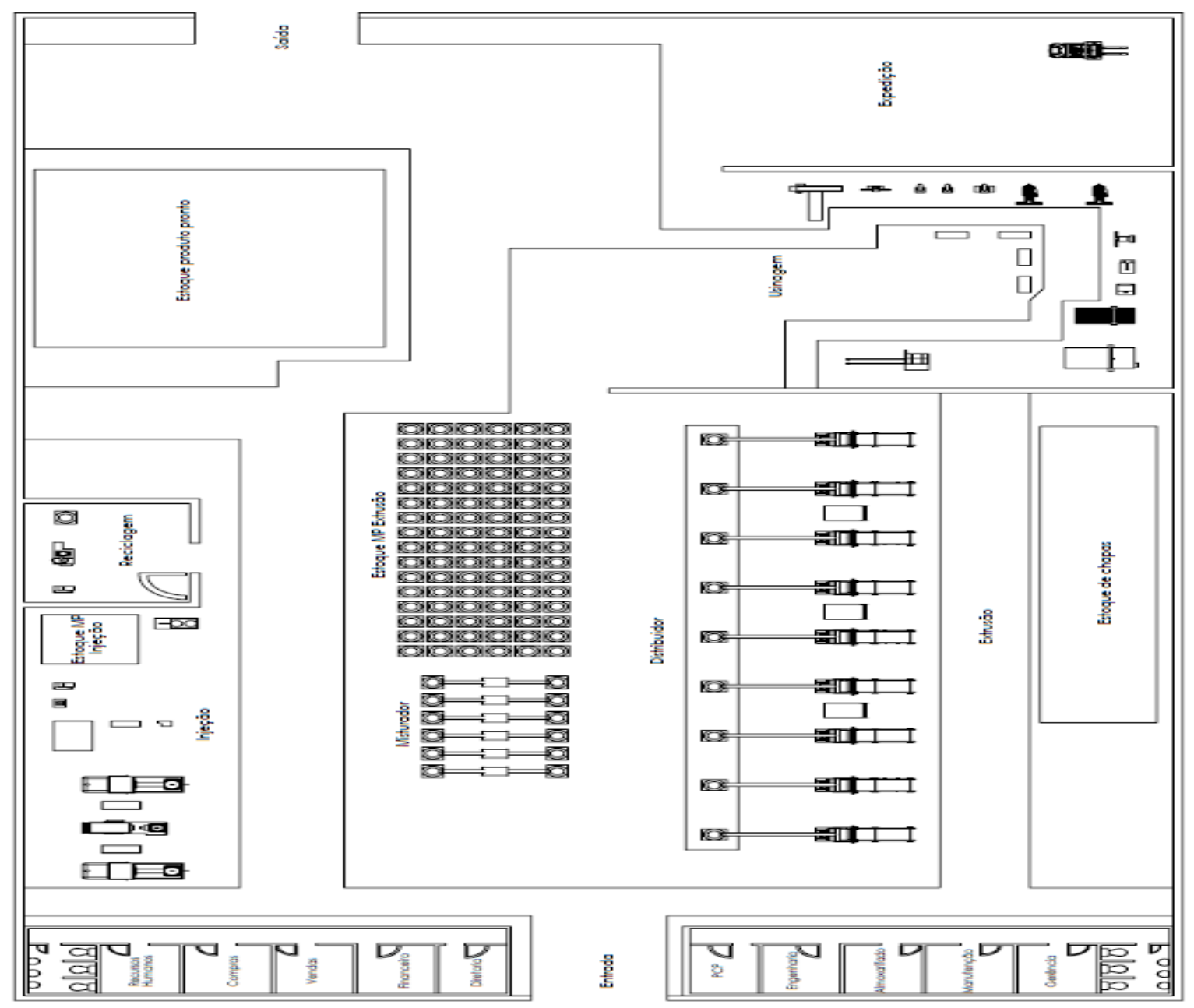

Figura 8: Proposta documentada do novo arranjo físico.

Ademais, na proposta apresentada, existe a possibilidade de ampliação da estrutura sem comprometimento dos processos produtivos, bem como a aplicação de conceitos mais complexos de Lean Manufacturing. Pode-se salientar também, que o layout proposto foi desenvolvido levando em consideração as análises realizadas pelo mapeamento de fluxo de valor.

A questão estratégica é de fato norteadora da forma com que o layout será estruturado. Sendo assim, considerando que a estratégia da empresa é a flexibilidade, esse novo arranjo busca ser flexível no que tange a trocas de ferramentas, o abastecimento de matérias primas, aos estoques intermediários que precisam fluir e também à movimentação de máquinas.

\subsection{VSM a partir da nova proposta de layout}

A partir da elaboração da proposta realizou-se um novo mapeamento do fluxo de valor agora considerando as alterações propostas (Figura 9). 


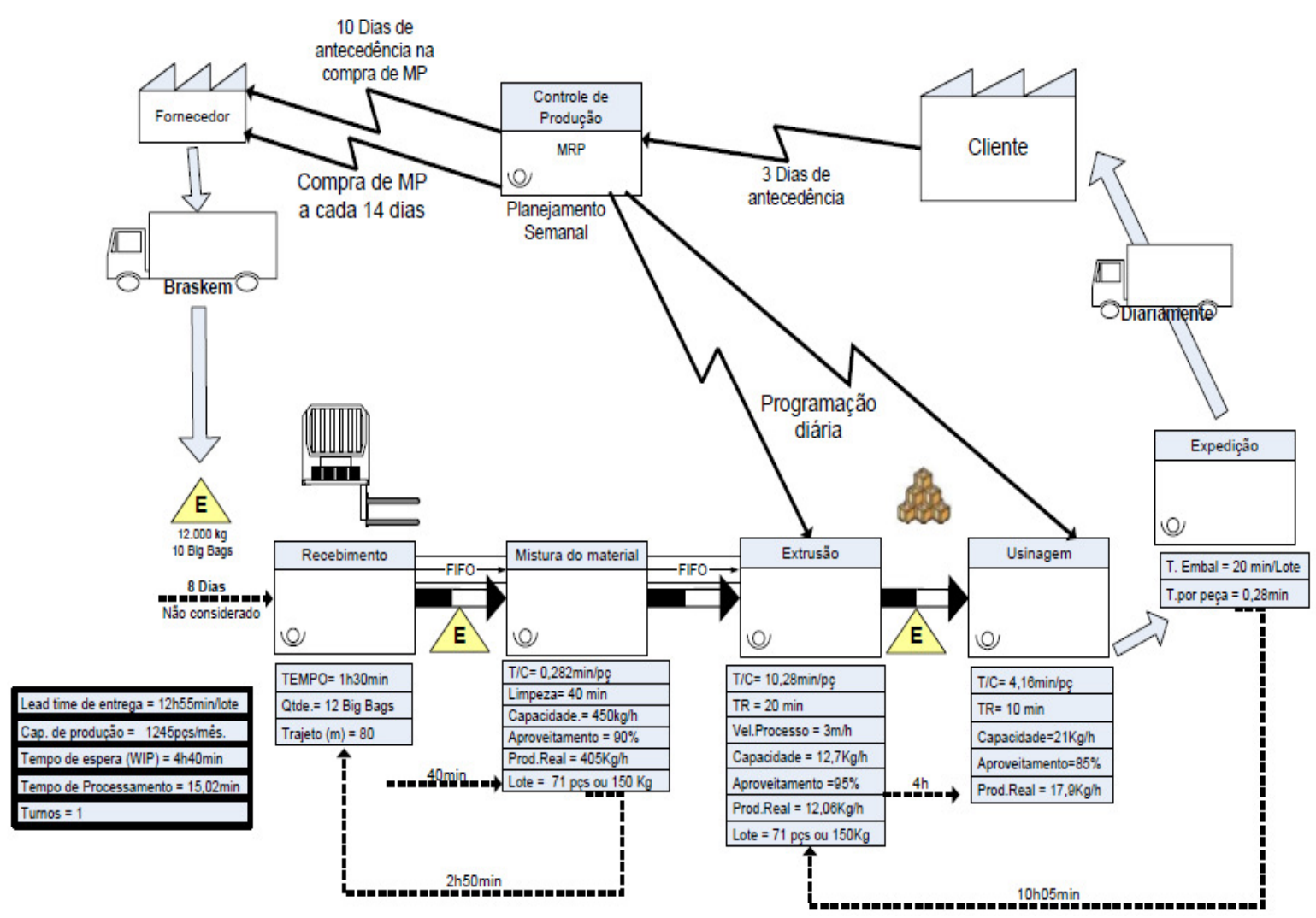

Figura 91: Mapa de fluxo de valor a partir da proposta documentada.

Analisando o mapeamento do fluxo de valor da proposta de arranjo físico ilustrado pela Figura 9, tem-se que as grandes diferenças quantitativas em relação a ganhos nos processos estão na diminuição do lead time de entrega que pode ter uma redução de $37,71 \%$ em relação ao valor encontrado no layout atual. Na capacidade de produção, através dos cálculos, obteve um aumento de $62,25 \%$, ou seja, demonstra que pode haver um ganho expressivo em termos de produtividade.

O tempo de espera considerando a estrutura do prédio poderá vir a ter uma redução de $62,86 \%$ em relação ao que se tem agora e o tempo de processamento pode vir a ter uma redução de $24,4 \%$. Esses valores evidentemente são estimados, e foram calculados através de simulação, considerando um fluxo contínuo dos processos que é o que o arranjo proposto possibilita. É válido salientar que mesmo sendo valores estimados, eles são próximos aos da realidade, possíveis de serem atingidos, visto que todos os dados e análises aqui apresentados são reais e refletem todas as questões que fazem parte do contexto real dos processos da manufatura da empresa.
Ao analisar o mapeamento do fluxo de valor ilustrado na Figura 9, percebe-se que os valores mostrados nos campos informativos, demonstram que em cada um dos processos há valores otimizados, ou seja, em cada um deles pode haver melhorias no que tange a redução de tempos e aumento de produtividade. Essas melhorias analisadas foram obtidas com a aplicação em partes chave dos processos, como por exemplo, na questão do recebimento, onde há clara identificação dos espaços, sendo que nestes, somente há equipamentos que são estritamente necessários. Tais mudanças remetem a implementação dos 5Ss.

$\mathrm{Na}$ etapa de mistura do material, o projeto de distribuição, possibilitará que o processo seja automatizado, fazendo com que não seja necessário o abastecimento da matéria prima pelos operadores, diminuindo o tempo de ciclo e aumentando expressivamente a capacidade de mistura.

$\mathrm{Na}$ extrusão com aplicação dos conceitos de troca rápida de ferramenta, onde serão introduzidos entre máquinas, carrinhos completos para o setup, e também com a questão da troca hidráulica de ferramenta, poderá haver 
uma redução estimada de 93,33\%, ou seja, um ganho enorme em termos de tempo, e também na usinagem com a adoção de dispositivos simples de troca de ferramenta, poderá ser diminuído o tempo em $33 \%$ de acordo com o projeto de troca rápida que está sendo desenvolvido.

\section{CONSIDERAÇÕES FINAIS}

O estudo do layout industrial nas empresas tem se demonstrado cada vez mais necessário, pois no cenário competitivo em que atuam, diferenciar-se dos concorrentes por meio da otimização de seus processos, garante a eficácia dos processos e aumento de sua produtividade. Fator como melhoria da qualidade, menores estoques e um arranjo físico adequado atrelado à estratégia organizacional bem definida proporciona as organizações um considerável ganho na manufatura.

No presente trabalho foram abordadas as etapas que devem ser seguidas para a elaboração de uma proposta de layout, trazendo em sua concepção os conceitos de manufatura enxuta. Onde há necessidade de avaliar o tipo de processo, as máquinas, o fluxo, o mercado, além de fatores externos também. É válido salientar que a elaboração pode evidentemente ser feita de outras formas, porém torna-se imprescindível avaliar as estratégias adotada pela empresa.

O objetivo principal, atendido neste trabalho, foi o desenvolvimento de uma proposta de arranjo físico que considera os conceitos básicos da manufatura enxuta para uma indústria de transformação de termoplásticos. No desenvolvimento desse novo arranjo foi analisado o layout atual, onde se diagnosticou a situação atual, identificaram-se os desperdícios, o tipo de processo da empresa, o fluxo, e dentro disso, foi realizado um mapeamento do fluxo de valor desse arranjo atual.

Posteriormente a isso, elaborou-se uma proposta, adequando nos processos onde foi possível, algumas ferramentas e metodologias da manufatura enxuta, após isso, mapeou-se o fluxo de valor em cima da proposta e analisou-se as vantagens a partir da manufatura enxuta. As estimativas de ganhos foram realizadas nos processos onde foi possível analisar os ganhos com a utilização das ferramentas.

Em todos os processos da manufatura da empresa foram mapeadas as perdas existentes, nesse mapeamento foi considerado a relação com as sete perdas de Ohno, posteriormente os estudos tiveram o objetivo de reduzir ou até mesmo eliminar essas perdas através das ferramentas de manufatura enxuta. Essas ferramentas foram adequadas na proposta do novo layout.

Este estudo, por possuir uma relação abrangente com as áreas produtivas organizacionais, poderá auxiliar e até mesmo nortear trabalhos similares para empresas que julgarem necessárias as mudanças para um novo arranjo físico, contemplando ferramentas da manufatura enxuta, como os cinco sensos, o mapeamento de fluxo de valor e a troca rápida de ferramenta. Essa análise se justifica, pois vai ao encontro da melhoria e otimização dos processos e resultados dentro das empresas, pelo fato de diminuir ou até mesmo eliminar perdas, reduzindo estoques, movimentações, defeitos, transporte, espera, processamento e superprodução.

\section{REFERÊNCIAS BIBLIOGRÁFICAS}

ALMEIDA, C, A. 2007. Implantação da manufatura enxuta em uma célula de produção. Trabalho de conclusão de curso, Universidade do estado de Santa Catarina - UDESC.

BAZARRA, M. F. S., SMITH, T., DAHLGAARD-PARK, S. M. 2009. Lean-kaisen public service: an empirical approach in Spanish local governments. The TQM Journal, 21, 143-167.

BORBA, M. 1998. Arranjo físico. Santa Catarina: Universidade Federal de Santa 
Catarina. Apostila do curso de Engenharia de Produção.

BORTOLOTTI, T., DANESE, P., ROMANO, P. 2012. Assessing the impact of just-in-time on operational performance at varying degrees of repetitiveness. International Journal of Production Research, 51, 1117-1130.

BRAGLIA, M., CARMIGNANI, G., ZAMMORI, F. 2006. A new value stream mapping approach for complex production systems. International Journal of Production Research, 44, 3929-3952.

CARVALHO, D. S., RESENDE, D. P., SOUZA, N. S. H., LIMA, R. F. 2010. Implantação de um arranjo físico (layout) e sua relevância para a dinamicidade organizacional no processo de produção: revisão Bibliográfica. Interciências, 2, 111.

CAUCHICK, M. P. A. 2012. Metodologia de pesquisa em engenharia de produção e gestão de operações. Elsevier, Rio de Janeiro.

CORRÊA, H. L., GIANESI, I. G. N. 1996. Just in time, MRP e OPT: Um enfoque estratégico. São Paulo, Atlas.

COSTA, J. A. 2004. Otimização do layout de produção de um processo de pintura de ônibus. Dissertação de Mestrado, Universidade federal do Rio Grande do sul.

COTTYN, J., VAN LANDEGHEM, H., STOCKMAN, K., DERAMMELAERE, S. 2011. A method to align a manufacturing execution system with Lean objectives. International Journal of Production Research, 49, 4397-4413.

FIGUEIREDO, K. 2006. A Logística Enxuta. Centro de Estudos em Logística - COPPEAD, Universidade Federal do Rio de Janeiro.
GAITHER, N., E FRAZIER, G. 2001. Administração da Produção $e$ Operações. São Paulo, Pioneira.

GAVIOLI G., SIQUEIRA, M. C. M., SILVA, P. H. R. Aplicação do programa 5S em um sistema de gestão de estoques de uma indústria de eletrodomésticos e seus impactos na racionalização de recursos. $12^{\circ}$ SIMPOI, Simpósio De Administração Da Produção, Logística E Operações Internacionais, 2009, São Paulo, Brasil, 1-13.

HINES, P., RICH, N. 1997. The seven value stream mapping tools. International Journal of Operations \& Production Management, 17, 46-64.

JUNIOR, J. L. 2012. A produção enxuta em um sistema de fabricação contínuo: aplicação da simulação discreta estocástica na indústria de condutores elétricos. Tese de Doutorado, Universidade Estadual Paulista.

LU, J.-C., YANG, T., WANG, C.-Y. 2011. A lean pull system design analysed by value stream mapping and multiple criteria decision-making method under demand uncertainty. Journal of Computer Integrated Manufacturing, 24, 211-228.

MACHLINE, C., MOTTA, I. S., SCHOEPS, W., WEIL, K. E. 1990. Manual de administração da produção. São Paulo, FGV.

NASCIMENTO, D. S. 2002. Gestão da Qualidade Total: uma proposta de implantação do programa de gestão de qualidade $5 S$ na Biblioteca Setorial do Centro de Ciências Sociais Aplicadas da $U F P B$. Trabalho de conclusão de curso, Universidade Federal de Paraíba.

NAZARENO, R, R., RENTES, A, F., SILVA, A, L. Implantando técnicas e conceitos da produção enxuta integradas à dimensão de análise de custos. ENEGEP Encontro Nacional de Engenharia de Produção, 2001, Salvador, Brasil, 1-8. 
OHNO, T. 1997. O Sistema Toyota de Produção: Além da produção em larga escala. Porto Alegre, Bookman.

PDAPL. 2007. Plano de desenvolvimento de arranjo produtivo local. Arranjo Produtivo local de plásticos da região do grande ABC. São Paulo. Disponível em: $<$ http://www.mdic.gov.br/arquivos/dwnl_ 1248288417.pdf >.Acesso em: 15 abr. 2015.

REIS, A. C. C. Implementação da manufatura enxuta na General Motors do Brasil: avaliação do desdobramento do plano de negócios na planta S-10. 2004. Dissertação Mestrado, Universidade de Taubaté.

ROSA, A. B. 2011. Estudo da influência da adoção das práticas de manufatura enxuta na definição de prioridades competitivas: uma pesquisa survey em empresas da região de Bauru-SP. Dissertação de Mestrado, Universidade Estadual Paulista.

ROTHER, M., SHOOK, J. 2005. Aprendendo a enxergar. São Paulo, Lean Institute Brasil.

SALAZAR, A. F., VARGAS, L. C., ANASCO, C. E., OREJUELA, J. P. 2010. Propuesta de distribución en planta bietapa en ambientes de manufactura flexible mediante el proceso analítico jerárquico. Rev. EIA. Esc. Ing. Antio., 14, 161-175.

SANDREA, M., BOSCÁN, M. 2007. Desarrollo endógeno como alternativa para el éxito de empresas de reducido. Espacio Abierto, 3, 555-571.

SHINGO, S. 1996. O Sistema Toyota de Produção do ponto de vista da Engenharia de Produção. Porto Alegre, Artes Médicas.

SHINGO, S. 1996. Sistemas de produção com estoque zero: O sistema Shingo para melhorias contínuas. Porto Alegre, Artes Médicas.
SHINGO, S. 2002. O Sistema Toyota de Produção do Ponto de Vista da Engenharia de Produção. Porto Alegre, Bookman.

SILVA, E. L., CASSIANO, D. A., HABER, J., LOURENÇO, S. R. 2012. Aspectos ergonômicos no planejamento e execução de projetos: estudo de caso de um centro de distribuição de produtos têxteis. Revista de Gestão e Projetos GeP, 3, 156-180.

SLACK, N., CHAMBERS, S., JOHNSTON, R. 2002. Administração da Produção. São Paulo, Atlas.

SOSSANOVICZ. R. H. 2010. Vantagens da aplicação da logística Lean no layout de estoques e transportes de materiais. Trabalho de conclusão de curso, Universidade Estadual de Santa Catarina.

VEIGA, G. L., LIMA, E. P., COSTA, S. E. G. 2008. Uma discussão sobre o papel estratégico do modelo de produção enxuta. Sistemas \& Gestão, 3, 92-113.

WANG, G., YAN, Y., ZHANG, X., NING, R., WU, Z. 2008. Integrating simulation optimization with VR for facility layout evaluation. International Conference on Information Management and Industrial Engineering. Taipei.

YANG, T., HSIEH, C.-H., CHENG, B.Y. 2011 Lean-pull strategy in a re-entrant manufacturing environment: a pilot study for TFT-LCD array manufacturing. International Journal of Production Research, 49, 1511-1529. 